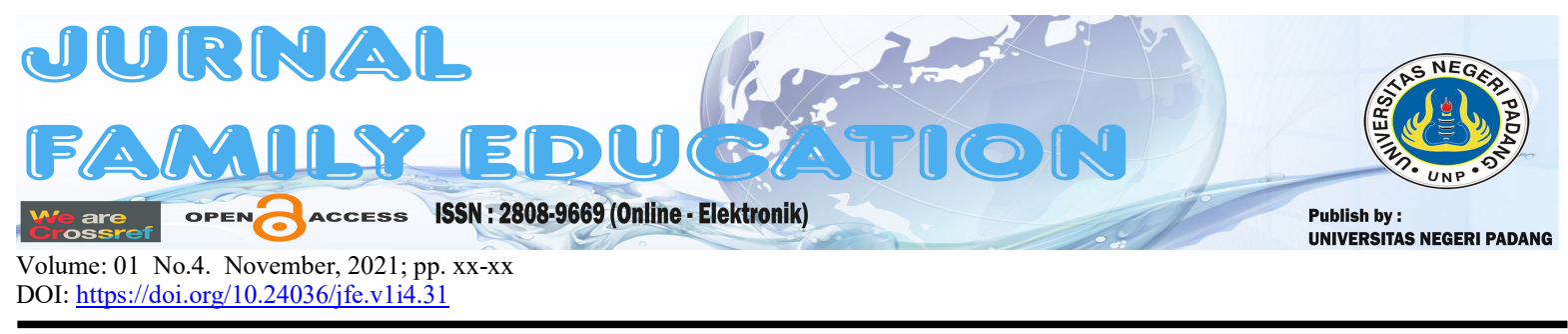

\title{
Pengaruh Bermain Perkusi Bambu Terhadap Kecerdasan Musikal Anak Di Raudhatul Athfal
}

\author{
Miftahul Khaira, Indra Yeni \\ Universitas Negeri Padang \\ * e-mail: miftahulkhaira9mei@gmail.com; indrayeni.30031971@gmail.com
}

\begin{abstract}
This study aims to determine the effect of playing bamboo percussion on the musical intelligence of children in Raudhatul Athfal Arafah Padang. The musical intelligence of children at Raudhatul Athfal Arafah Padang has not developed well, because of the low musical understanding of children in recognizing tempo, it can be seen when children are singing that many do not match the beats played by the teacher with a tambourine musical instrument or when clapping. The limited facilities and infrastructure for playing music for children have resulted in no opportunity for children to develop music playing activities at school. This study uses a quantitative approach with a quaishi experimental design, the data collection technique in this study is an action test on students. This research was conducted at Raudhatul Athfal Arafah Padang which consisted of two classes, one class was used as the experimental class group and the other class was used as the control class group. The experimental class group was 12 people and the control class group was 12 people. The data analysis technique in this study used the Normality Test, Homogeneity Test, and Hypothesis Testing. The results of the Hypothesis Testing in the post-test obtained tcount $>$ ttable where $9.23>2.073$ as evidenced by the significant level $=0.05$ this means that there is a significant difference between the results of the intelligence of children in the experimental class playing bamboo percussion compared to the control class using clap.
\end{abstract}

Keywords: Bamboo Percussion, Musical Intelligence, Early Childhood derivative works and remixes based on it only for non-commercial purposes.

\section{PENDAHULUAN}

Pendidikan pada anak usia dini di Raudhatul Athfal merupakan pendidikan yang berada pada jalur pendidikan formal, pendidikan pada RA dapat membentuk individu yang berilmu, berpengetahuan yang luas dan membentuk hubungan sosial yang baik. Raudhatul Athfal (RA) sebagai satuan pendidikan Anak Usia Dini bebasis Islam di bawah pembinaan Kementrian Agama. Raudhatul Athfal memiliki perbedaan dengan pendidikan Anak Usia Dini secara umum. RA menitikberatkan pendidikan pada aspek perkembangan anak, transformasi dan internalisasi nilai-nilai keislaman.Novela (2020:33) menjelaskan bahwa pendidikan anak usia dini merupakan upaya dalam membentuk kesiapan untuk masa selanjutnya, tujuan menyelenggarakan pendidikan pada anak usia adalah memberikan fasilitas untuk membantu proses perkembangan dan pertumbuhan secara menyeluruh.

Dalam PERMENDIKBUD no.146 Tahun 2014 Tentang Kurikulum 2013 Pendidikan Anak Usia Dini menerangkan pada pasal (1) pendidikan anak usia dini, merupakan suatu upaya pembinaan yang ditujukan kepada anak sejak lahir sampai usia 6 (enam) tahun yang dilakukan 
dengan pemberian rangsangan pendidikan untuk membantu pertumbuhan dan perkembangan jasmani dan rohani agar anak memiliki kesiapan dalam memasuki pendidikan lebih lanjut. Dalam PERMENDIKBUD no 137 tahun 2014 pasal 10 butir (7) menerangkan bahwa seni sebagaimana dimaksud memiliki kemampuan untuk mengeksplorasi dan mengekspresikan diri, berimajinasi dengan gerakan, musik, drama, dan beragam bidang seni lainnya serta mampu mengapresiasi karya seni, musik, gerak, tari dan drama. Salah satu jenis kesenian yang dapat dikembangkan pada anak yaitu seni musik.

Seni musik adalah seni yang berhubungan dengan bunyi-bunyian yang dihasilkan oleh suatu benda atau vokal yang dapat mengeluarkan bunyi atau suara, mengembangakan seni musik pada anak usia dini dapat membantu berbagai jenis aspek perkembangan lainnya yaitu, motorik kasar, motorik halus, bahasa, sosial emosional, dan kognitif. Sheppard dalam Putri (2020:464) menyatakan bahwa musik merupakan kemampuan dalam membantu berbahasa dengan mendorong kreatifitas, imajinasi, dalam perkembangan masa kanak-kanak.

Berdasarkan observasi yang peneliti lakukan di RA Arafah Padang, ditemukan masalah bahwa rendahnya pemahaman musikal anak dalam mengenal tempo, terlihat pada saat anak sedang bernyanyi banyak yang tidak sesuai tempo yang dimainkan guru dengan alat musik tamborin atau pada saat bertepuk tangan. Pada saat bernyanyi anak memiliki semangat dan mengikuti guru dengan ikut bertepuk tangan namun tidak sesuai dengan ketukan yang seharusnya. Hal ini perlu diatasi agar perkembangan kecerdasan musikal pada anak dapat terstimulasi dengan baik. Guru dapat menggunakan alat musik perkusi sederhana untuk membantu anak dalam mengatasi keterbatasan anak dalam mengenal musik, mengikuti tempo, dan membantu merangsang kecerdasan musikalnya.

Sembiring (2017:66) kecerdasan yaitu suatu kemampuan yang digunakan untuk menjelaskan tentang kemampuan menalar, merencanakan, memecahkan masalah, berpikir abstrak, memiliki gagasan, dan kemampuan berbahasa. Banyak jenis kecerdasan yang dimiliki oleh seorag individu yang dapat dikembangkan dari sejak usia dini, kecerdasan yang dimaksud adalah kecerdasan majemuk (multiple intellegences).

Kecerdasan majemuk merupakan salah satu teori belajar yang dikemukakan oleh Howard Gardner yang merupakan seorang ahli pendidikan dan prikologi yang berasal dari Amerika, teori belajar ini dikenalkan pertama kalinya pada tahun 1983. Suparno dalam Machali (2014:36) Sembilan kecerdasan majemuk itu adalah, Kecerdasan Linguistik (Word Smart), Kecerdasan Matematis-Logis (Logical-Mathematical Intelligence), Kecerdasan Spasial/Ruang-Visual (VisualSpatial Intellegence), Kecerdasan Musikal (Musical Intellegence), Kecerdasan Kinetetik (Kinesthetic Intellegence), Kecerdasan Interpersonal (Interpersonal Intellegence), Kecerdasan Intrapersonal (Intrapersonal Intellegence), Kecerdasan Naturalis (Naturalist Intellegence), Kecerdasan Eksistensial (Existensial Intellegence).

Kecerdasan majemuk yang disampaikan oleh Garnder ini memiliki banyak ragam jenis kecerdasan yang dapat dikembangkan. Salah satu jenis kecerdasan majemuk itu adalah kecerdasan musikal, kecerdasan musikal merupakan salah satu kemampuan yang harus dikembangkan pada anak usia dini, kecerdasan musikal ini merupakan salah satu kemampuan dalam mengingat irama pada lagu dengan ketukan-ketukannya. Mengembangkan kecerdasan musikal menurut Sujiono dan Sujiono dalam Yeni (2015:77) : (a) memberikan kesempatan kepada anak dalam melihat kemampuan yang ada dalam dirinya (b) mengadakan kegiatan yang khusus yang dapat mengembangkan kecerdasan musikal (c) memberi penghargaan terhadap hasil karya anak dari 
pengalaman empiris yang praktis (d) mengajak anak untuk bernyanyi menggunakan syair-syair yang sederhana dengan irama dan birama yang mudah untuk diikuti anak.

Untuk membantu berkembangnya kecerdasan musikal pada anak dapat dilakukan dengan bermain musik dan bernyanyi. Bermain musik pada anak dapat dilakukan dengan permainan alat musik sederhana yang dapat dimainkan anak dengan mudah dan menarik sambil membawakan lagu-lagu untuk dinyanyikan. Dengan menggunakan alat musik perkusi dapat membantu proses perkembangan kecerdasan musikal anak.

Perkusi merupakan suatu benda yang dapat menghasilkan bunyi dengan cara dipukul, dikocok, digosok, diadukan, digesek, atau dengan cara apapun yang membuat benda tersebut mengeluarkan bunyi. Sehingga dapat menyusun pola irama agar menghasilkan bunyi yang indah didengar saat dimainkan. Dengan bermain alat musik perkusi sederhana akan membantu anak dalam pengenalan musik secara nyata. Anak dapat mencoba sehingga memberikan kesempatan kepada anak dalam mengembangkan ide-ide kreatifitasnya dalam memainkan alat musik perkusi. Kemudian kecerdasan musikal pada anak menjadi terstimulasi dengan baik. Alat musik perkusi jika dimainkan oleh anak akan memiliki banyak manfaat, diantaranya membantu memfokuskan perhatian anak yang akan berpengaruh pada daya ingat anak (Sheppard dalam Yeni, 2015:77).

Penelitian ini bertujuan untuk mengetahui pengaruh bermain perkusi bambu terhadap kecerdasan musikal anak di RA Arafah Padang.Alat musik yang digunakan dalam penelitian ini adalah perkusi bambu. Perkusi ini bermanfaat untuk mengembangkan kemampuan kecerdasan musikal anak, karena alat perkusi ini membuat anak lebih tertarik untuk mencoba memainkannya, hal ini meningkatkan rasa ingin tahu anak dalam mengenal musik. Cara memainkannya juga sangat sederhana, anak dapat memukul bagian bambu yang tinggi atau yang rendah sehingga menghasilkan suara yang berbeda, perkusi bambu ini akan membantu anak dalam melatih kecerdasan musikalnya terutama pada tempo.

\section{METODE}

Jenis penelitian ini adalah kuantitatif dengan metode eksperimen dalam bentuk quaishi experimental (eksperimen semu). Siyoto dan Sodik (2015:22) mengemukakan metode eksperimen adalah sebuah metode penelitian yang memiliki tujuan untuk menjelaskan suatu hubungan sebabakibat (kausalitas) antara dengan satu variabel dengan variabel yang lainnya (variabel $\mathrm{X}$ dengan variabel Y). Sugiyono (2018: 111) menyatakan metode eksperimen merupakan metode yang digunakan untuk mengetahui pengaruh dari variable independent (treatment/perlakuan) pada variable dependen (hasil) dengan kondisi yang terkendalikan. Penelitian ini mengungkapkan seberapa besar pengaruh bermain perkusi bambu terhadap kecerdasan musikal pada anak di Raudhatul Athfal Arafah Padang, dengan memberikan bandingan hasil belajar pada kelas eksperimen dengan kelas kontrol.

Dalam penelitian ini penulis menggunakan tes perbuatan yang menuntut jawaban dari anak dalam bentuk tindakan, perilaku, dan perbuatan. Titik tolak dari penyusunan instrumrn adalah variabel-variabel penelitian yang berasal dari kompetensi dasar selanjutnya diberikan indikator yang akan diukur. Dari indikator ininakan dijabarkan menjadi butir-butir pertanyaan dan pernyataan.

Teknik analisis data yang digunakan dalam penelitian ini adalah membandingkan perbedaan dari dua rata-rata nilai, sehingga dilakukan dengan uji-t (t-test). Namun sebelum itu, terlebih dahulu melakukan uji normalitas dan uji homogenitas. 


\section{HASIL PENELITIAN}

Data yang dideskripsikan dalam penelitian ini terdiri dari dua kelompok yaitu data dari hasil pre-test (kemampuan awal) dan post-test (hasil akshir) perkembangan kecerdasan musikal anak sebelum diberikan treatment terhadap kelompok eksperimen dan kelompok kontrol. Data yang diambil adalah data tentang kecerdasan musikal anak yang menggunakan alat musik perkusi. Data diolah menggunakan uji hipotesis. Kegiatan dilakukan sebanyak 10 kali pertemuan, 5 kali pada kelas eksperimen dan 5 kali pada kelas kontrol.

Tabel 1.Hasil Perhitungan Pengujian Dengan t-test

\begin{tabular}{|c|c|c|c|c|c|l|}
\hline No & Kelompok & $\mathbf{N}$ & $\begin{array}{c}\text { Hasil Rata- } \\
\text { rata }\end{array}$ & $\mathbf{t}_{\text {hitung }}$ & $\begin{array}{c}\mathbf{t}_{\text {tabel } \boldsymbol{\alpha}} \\
\mathbf{0 , 0 5}\end{array}$ & Keputusan \\
\hline 1 & Eksperimen & 12 & 61,81 & \multirow{2}{*}{1,66} & 2,073 & Terima $\mathrm{H}_{\mathrm{o}}$ \\
\hline 2 & Kontrol & 12 & 54,87 & & \\
\hline
\end{tabular}

t tabel untuk taraf nyata $\alpha=0,05(5 \%)$ dengan df sebesar 22 adalah $=2,073$. Dengan

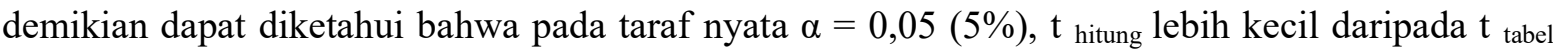
$(1,66<2,073)$. Jadi, dapat disimpulkan bahwa tidak terdapat perbedaan signifikan antara hasil pre-test (hasil awal) anak di kelas eksperimen dan kelas kontrol dalam kecerdasan musikal anak di Raudhatul Athfal Arafah Padang.

Tabel 2. Hasil Perhitungan Pengujian Dengan t-test

\begin{tabular}{|c|c|c|c|c|c|c|}
\hline No & Kelompok & $\mathbf{N}$ & $\begin{array}{c}\text { Hasil Rata- } \\
\text { rata }\end{array}$ & $\mathbf{t}_{\text {hitung }}$ & $\begin{array}{c}\mathbf{t}_{\text {tabel } \boldsymbol{\alpha}} \\
\mathbf{0 , 0 5}\end{array}$ & Keputusan \\
\cline { 1 - 4 } 1 & Eksperimen & 12 & 90,97 & \multirow{2}{*}{9,23} & 2,073 & Terima $\mathrm{H}_{\mathrm{o}}$ \\
\hline 2 & Kontrol & 12 & 60,07 & \multirow{2}{*}{ Tel } & & \\
\hline
\end{tabular}

t tabel untuk taraf nyata $\alpha=0,05(5 \%)$ dengan df sebesar 22 adalah $=2,073$. Dengan demikian dapat diketahui bahwa pada taraf nyata $\alpha=0,05(5 \%), \mathrm{t}_{\text {hitung }}$ lebih besar daripada $\mathrm{t}$ tabel $(9,23<2,073)$. Jadi, dapat disimpulkan bahwa $\mathrm{H}_{\mathrm{a}}$ diterima yaitu, terdapat perbedaan signifikan antara hasil post-test (hasil akhir) anak di kelas eksperimen dan kelas kontrol dalam kecerdasan musikal anak di Raudhatul Athfal Arafah padang.

Tabel 3.Perbandingan Hasil Perhitungan Nilai Pre-Test Dan Nilai Post-Test

\begin{tabular}{|c|c|c|c|c|}
\hline \multirow{2}{*}{ Variabel } & \multicolumn{2}{|c|}{ Pre-test } & \multicolumn{2}{c|}{ Post-test } \\
\cline { 2 - 5 } & Eksperimen & Kontrol & Eksperimen & Kontrol \\
\hline Nilai Tertinggi & 75 & 70,83 & 100 & 79,17 \\
\hline Nilai Terendah & 50 & 50 & 75 & 50 \\
\hline Rata-rata & 61,81 & 54,87 & 90,97 & 60,07 \\
\hline
\end{tabular}

Berdasarkan tabel di atas, terlihat perbendingan hasil perhitungan nilai pre-test dan nilai post-test. Pada pre-test nilai tertinggi yang diperoleh anak dalam kelas eksperimen yaitu 75 dan nilai terendah 50, dengan rata-rata 61,81. Sedangkan pada kelas kontrol nilai tertinggi yang diperoleh anak yaitu 70,83 dan nilai terendah 50 dengan rata-rata 54,87.Pada post-test nilai tertinggi yang diperoleh anak eksperimen yaitu 100 dan nilai terendah 75 dengan rata-rata 90,97 sedangkan pada kelas kontrol post-test nilai tertinggi yang diperoleh anak yaitu 79,17 dan nilai terendah 50 dengan rata-rata 60,07. Untuk lebih jelasnya dapat dilihat pada grafik berikut ini : 


\section{Grafik 1. Data Perbandingan Hasil Pre-Test Dan Post-Test Kemampuan Berbicara Anak Kelas Eksperimen Dan Kelas Kontrol}

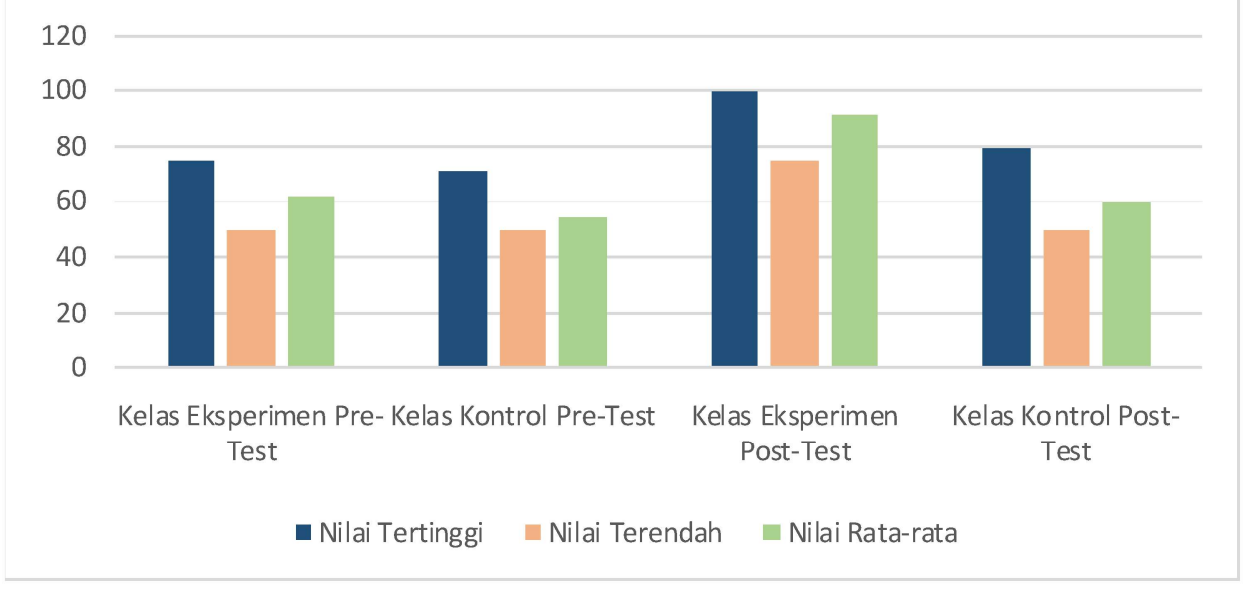

\section{PEMBAHASAN}

Musik merupakan suatu hal yang berhubungan dengan suara yang disusun dengan sedemikian rupa yang mengandung irama, lagu, nada, dan keharmonisan dari suara yang dihasilkan dari alatalat yang dapat menghasilkan sebuah irama. Musik adalah ungkapan atau sebuah ekspresi yang dilahirkan melalui bunyi yang bersumber dari alat musik atau suara manusia ( Yeni, 2018: 1). Sheppard dalam Putri (2020:464) menyatakan bahwa musik merupakan kemampuan dalam membantu berbahasa dengan mendorong kreatifitas, imajinasi, dalam perkembangan masa kanakkanak.

Menurut Sousa dalam Nasution (2016:12) musik dapat memberi efek kuat terhadap perkembangan otak dengan memberi stimulasi intelektual dan emosional.Menurut Putri (2012) musik bertujuan membuat suasana menjadi nyaman dan menyenangkan pada saat mendengarkan, menghayati, serta saat menikmati alunan musik. Musik juga menjadi alat komunikasi bagi setiap orang, dengan musik seseorang dapat menyampaikan bagaimana suasana hati dan perasaan yang sedang dialami. Sehingga pendengarnya menjadi mengetahui makna apa yang terkandung dalam sebuah musik yang diciptakan.

Bermain alat musik perkusi bambu ini tentu dapat memberikan kesempatan anak dalam bermain musik. Anak dapat merasakan dan melakukannya secara langsung. Bermain musik secara langsung anak dapat mengetahui mana ketukan dan mana tempo yang benar dalam bermain musik.

Hasil penelitian ini menunjukan bahwa permainan alat musik perkusi bambu ini lebih berpengaruh digunakan untuk mengembangkan kecerdasan musikal anak dibandingkan mengembangkan kecerdasan musikal anak dengan melakukan tepuk tangan. Hal ini tampak pada anak yang lebih antusias dalam bermain musik karena alat musik yang di gunakan terlihat unik dan cara memainkannya dapat dilakukan dengan mudah, yaitu dengan cara memukulkan tongkat pada bambu yang tinggi atau yang rendah. Anak mampu melakukan ketukan dengan memainkan pola irama dengan tanda birama 4/4, 2/4 dalam kelompok. Anak cepat dalam meniruka ketukan yang dicontohkan oleh guru. Pola yang diberikan kepada anak merupakan pola irama dengan ketukan yang mudah. Hal ini dilakukan berulangkali sehingga anak mampu memberikan kesan serentak dalam bernyanyi dan bermain alat musik. 
Menurut Jamalus dalam Yeni (2010:46) salah satu unsur terpenting dalam musik adalah pola irama dan tempo. Kemampuan anak dalam bermain pola irama dan tempo ini yaitu merupakan kemampuan dasar yang perlu dikuasai dalam belajar musik dan hal ini yang mampu mengembangkan kecerdasan musikal anak Shepard dalam Yeni (2015:77) yang menyebutkan bahwa memainkan alat musik dapat memberikan manfaat salah satunya dapat membantu memfokuskan perhatian dan berpengaruh terhadap daya ingat anak.Menurut Kurniawan (2019:5) juga menyatakan bermain musik perkusi dapat melatih rasa musikal anak. Yang dimana perkembangan tersebut dapat dilihat dari perilaku anak yang mampu menirukan pola irama yang didengarnya.

Berdasarkan hasil pre-test kecerdasan musikal anak pada kelas ekperimen dan kelas kontrol pada diperoleh angka rata-rata kelas eksperimen yaitu 61,81 dan rata-rata kelas kontrol yaitu 54,87. Berdasarkan hasil analisis data yang telah dilakukan bahwa $t_{\text {hitung }}$ sebesar 1,66 dibandingkan dengan $\alpha=0,05 \mathrm{t}_{\text {tabel }}=2,073$ dengan derajat kebebasan $\mathrm{dk}\left(\mathrm{N}_{1}-1\right)+\left(\mathrm{N}_{2}-1\right)=22$. Dengan demikian $\mathrm{t}_{\text {hitung }}<\mathrm{t}_{\text {tabel }}$, yaitu 1,66 $<2,073$, maka dapat dikatakan bahwa hipotesis $\mathrm{H}_{a}$ ditolak atau $\mathrm{H}_{o}$ diterima.

Jadi dapat disimpulkan bahwa tidak terdapat perubahan yang signifikan dalam penggunaan alat musik perkusi bambu terhadap kecerdasan musikal anak di Raudhatul Athfal Arafah Padang. Pada saat peneliti menggunakan alat musik perkusi bambu pada kelas eksperimen (B1) di RA Arafah Padang pada pre-test terlihat anak belum mampu bermain perkusi bambu sesuai tempo. Ketukan yang dilakukan anak masih tidak beraturan, dan bahkan sebagian anak hanya melihat teman-teman nya bermain alat musik tersebut. Dan tampaknya anak belum fokus terhadap alat musik perkusi bambu yang akan di mainkanya, hal ini juga terjadi pada kelas kontrol yang dilakukan oleh guru kelas (B2) yang hanya melakukan dengan tepuk tangan.

Kemudian, berdasarkan hasil kecerdasan musikkal pada kelas eksperimen dan kelas kontrol pada post-test diperoleh angka rata-rata kelas eksprimen yaitu 90,97 dan angka rata-rata kelas kontrol yaitu 60,07. Berdasarkan hasil analisis data yang telah dilakukan bahwa $t_{\text {hitung }}$ sebesar 9,23 dibandingkan dengan $\alpha=0,05 \mathrm{t}_{\text {tabel }}=2,073$ dengan derajat kebebasan $\mathrm{dk}\left(\mathrm{N}_{1}-1\right)+\left(\mathrm{N}_{2}-1\right)=22$.

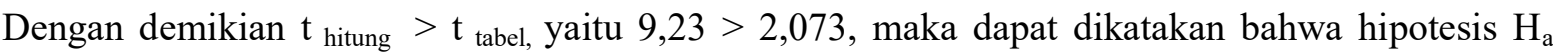
diterima atau $\mathrm{H}_{\mathrm{o}}$ ditolak.

Jadi dapat disimpilkan bahwa penggunaan alat musik perkusi bambu terbukti berpengaruh untuk mengembangkan kecerdasan musikal anak karena terdapat pengaruh yang siknifikan terhadap kercedasan anak di Rudhatul Athfal Arafah Padang pada kelas eksperimen (B1). Sedangkan dikelas kontrol (B2) menggunakan tepuk tangan untuk mengembangkan kecerdasan musikal anak, namun tepuk tangan kurang menarik perhatian karena tepuk tangan merupakan hal yang sudah biasa dilakukan anak

Berdasarkan pengamatan peneliti, hasil kecerdasan musikal pada anak dikelas eksperimen lebih baik daripada hasil kecerdasan musikal anak pada kelas kontrol. Hal ini dapat dilihat daei nilai rata-rata anak dikelas eksperimen yang lebih tinggi dari pada rata-rata dikelas kontrol. Maka dapat disimpulkan bahwa terdapat pengaruh dari penggunaan alat musik perkusi bambu terhadap kecerdasan musikal anak.

\section{SIMPULAN}

Berdasarkan hasil analisis data penelitian yang telah dilakukan, dapat diambil kesimpulan dari hasil penelitian yang dilakukan di Raudhatul Athfal Arafah Padang. Kecerdasan musikal anak di kelas eksperimen (B1) yang melakukan kegiatan perkusi bambu lebih berpengaruh 
dibandingkan dengan kelas kontrol (B2). Hasil uji hipotesis pada post-test didapat $t_{\text {hitung }}>t_{\text {tabel }}$ dimana 9,23>2,073 yang dibuktikan dengan taraf signifikan $\alpha=0,05$ ini berarti terdapat perbedaan yang signifikan antara hasil kecerdasan anak dikelas eksperimen dengan bermain perkusi bambu dibandingkan dengan kelas kontrol dengan menggunakan tepuk tangan. Dengan demikian bermain perkusi bambu berpengaruh terhadap kecerdasan musikal anak di Raudhatul Athfal Arafah padang.

\section{SARAN}

Berdasarkan hasil penelitian yang telah dijelaskan di atas, maka peneliti mengemukakan saran sebagai berikut: 1) Bagi anak, diharapkan agar kecerdasan musikal anak dapat berkembang dengan baik melalui pengunaan alat musik perkusi bambu; 2) Bagi Guru, dalam mengembangkan kecerdasan musikal anak hendaknya guru merancang kegiatan dan menggunakan media dan sarana dan prasarana yang bervariasi kepada anak melalui aktifitas yang lebih menarik. Diantaranya kegiatan pembelajaran dengan bermain alat musik perkusi; 3) Bagi Kepala Sekolah, dalam mengembangkan pembelajaran khususnya pengembangan kecerdasan musikal hendaknya sekolah dapat memberikan motivasi dan dorongan kepada Guru untuk menciptakan suatu pembaruan dalam kegiatan pembelajaran untuk mengembangkan kecerdasan musikal anak secara kreatif dan Inovatif; 4) Bagi Peneliti selanjutnya, diharapkan dapat meneliti dan menyampaikan gagasan tentang pembelajaran yang digunakan dalam mengembangkan kecerdasan musikal anak serta menjadi inspirasi dalam melakukan penelitian dimasa selanjutnya.

\section{REFERENSI}

Kurniawan, E. Y. (2019). Pendidikan Berbasis Kreativitas Pada Mahasiswa PGPAUD Melalui Pemanfaatan Media Barang-Barang Bekas Dalam Pembelajaran Musik Perkusi di Universitas Muhammadiyah Tangerang. Ceria: Jurnal Program Studi Pendidikan Anak Usia Dini, 9(2), 1-11.

Machali, I. (2014). Dimensi Kecerdasan Majemuk Dalam Kurikulum 2013. Insania: Jurnal Pemikiran Alternatif Kependidikan, 19(1), 21-45.

Nasution, R. A. (2016). Pembelajaran Seni Musik Bagi Pengembangan Kognitif Anak Usia Dini. Jurnal Raudhah, 4(1).

Novela, T., \& Yeni, I. (2020). Efektivitas Penggunaan Talempong Pacik Terhadap Kecerdasan Musikal Di Taman Kanak-Kanak Nurul Hidayah Bukittinggi. Jurnal Pendidikan Tambusai, 4(1), 33-38.

PERMENDIKBUD. 2014. Nomor 137 dan 146 tahun 2014. Tentang kurikulum 2013 pendidikan anak usia dini

Putri, N. (2012). Efektifitas penggunaan media video untuk meningkatkan pengenalan alat musik daerah pada pembelajaran IPS bagi anak tunagrahita ringan di SDLB 20 Kota Solok. Jurnal Ilmiah Pendidikan Khusus, 1(2), 318-328.

Putri, P. A., \& Ismet, S. (2020). Efektivitas Permainan Perkusi Kastanyet Terhadap Kecerdasan Musikal Anak. Jurnal pendidikan tambusai, 4(1), 464.

Putri, R. D., \& Yeni, I. (2020). Efektivitas Penggunaan Perkusi Sederhana Terhadap Kecerdasan Musikal Anak Di Taman Kanak-Kanak Assyofa Padang. Bunayya: Jurnal Pendidikan Anak, 5(2), 31-42.

Sembiring, M. A. (2017). Penerapan Metode Simple Additive Weighting Sebagai Strategi Pembinaan Kecerdasan Anak. JURTEKSI (Jurnal Teknologi dan Sistem Informasi), 4(1), 65-70.

Siyoto, S,\& Sodik, A. (2015). Dasar Metodologi Penelitian. Yogyakarta: Litersi 
Miftahul Khaira, Indra Yeni

media Publishing.

Sugiyono. 2012. Metode Penelitian Pendidikan Pendekatan Kuantitatif,

Kualitatif, dan R\&D. Bandung: Alfabeta

Sugiyono. 2017. Metode Penelitian Kuantitatif, Kualitatif dan R\&D. Bandung: Alfabeta

Sugiyono. 2018. Metode penelitian kuantitatif. Bandung: Alfabeta.

Yeni,I.(2010).Pengantar Seni Musik Untuk Pendidikan Anak Usia Dini. Padang: Sukabina Press

Yeni, I. (2015). Keefektifan Penggunaan Permainan Perkusi Sederhana Untuk

Meningkatkan Kecerdasan Musikal Anak Di Taman Kanak-Kanak. Jurnal Pendidikan dan Pembelajaran (JPP), 22(1), 76-81.

Yeni, I. (2018. Teknik Iringan Lagu Anak Penggunaan Keyboard Sebagai

Instrumen Ritmis. Jakarta: Kencana 